\title{
Anandamide-induced apoptosis in Chang liver cells involves ceramide and JNK/AP-1 pathway
}

\author{
MICHELA GIULIANO, GIUSEPPE CALVARUSO, ORNELLA PELLERITO, PATRIZIA PORTANOVA, \\ DANIELA CARLISI, RENZA VENTO and GIOVANNI TESORIERE
}

\author{
Dipartimento di Scienze Biochimiche, Università di Palermo, Policlinico, Palermo, Italy
}

Received November 30, 2005; Accepted January 11, 2006

\begin{abstract}
In the present study we demonstrate that anandamide, the most important endogenous cannabinoid, markedly induced apoptosis in Chang liver cells, an immortalized nontumor cell line derived from normal liver tissue, while it induced only modest effects in a number of hepatoma cell lines. The apoptotic effect was reduced by methyl- $\beta$-cyclodextrin, a membrane cholesterol depletor, suggesting an interaction between anandamide and the membrane microdomains named lipid rafts. Anandamide effects were mediated by the production of ceramide, as demonstrated by experiments performed with the sphingomyelinase inhibitor, desipramine, or with the sphingomyelinase activator, melittin. This conclusion was confirmed by the observation that exogenous C2-ceramide induced a remarkable apoptotic effect in the same cells. Anandamide-induced apoptosis in Chang liver cells involved oxidative stress and activation of p38/JNK pathway, which was accompanied by a remarkable increase in AP-1 DNA-binding activity. Moreover, the levels of both c-Jun and JunB, two components of the AP-1 complex, and those of FasL and Bim, two transcriptional targets of AP-1, also increased during anandamide treatment. In addition, anandamide increased the level of Bax and caused degradation of full-length Bid with the production of the active truncated form. These effects were accompanied by dissipation of mitochondrial transmembrane potential with the consequent activation of both caspase- 3 and caspase- 6 . On the contrary, in hepatoma cells, anandamide did not induce apoptotic effects and it was not possible to observe any increase in p38/JNK pathway and AP-1 activity after drug treatment. Our results suggest that the induction of cell death in nontumor Chang liver cells by anandamide was mediated by ceramide, JNK and AP-1 and was dependent on the activation of both the extrinsic and intrinsic pathways of apoptosis.
\end{abstract}

Correspondence to: Professor Giovanni Tesoriere, Dipartimento di Scienze Biochimiche, Policlinico, Via del Vespro 129, 90127 Palermo, Italy

E-mail: gtesor@unipa.it

Key words: anandamide, apoptosis, JNK/AP-1 pathway

\section{Introduction}

Anandamide ( $\mathrm{N}$-arachidonylethanolamine or AEA) is an endocannabinoid which belongs to a family of N-acylethanolamines produced by several mammal tissues (1-3). It acts as a lipid mediator through type- 1 and type- 2 cannabinoid receptors (CB1 and $\mathrm{CB} 2$ ) or the vanilloid receptor type 1 (VR1), which is the site of action of capsaicin (4-5). Recently, it has been reported that anandamide can exert cellular actions independently by its receptors through interaction with specific lipid microdomains of plasma membrane named lipid rafts (6).

Although the precise physiological role of endogenous cannabinoids has not been fully elucidated, anandamide has been implicated in a wide spectrum of central and peripheral effects, including modulation of memory, blood pressure, pain and control of immune system (7-8). More generally, it has been speculated that anandamide may control cell fate by modulating the choice between growth and death. Recent findings have focused on the antitumoral potential of anandamide for some transformed cell lines from glioma and human prostate or breast cancers (9-11). Anandamide might exert antitumor effects by means of several different mechanisms, including direct inhibition of cell growth, induction of cell death and/or inhibition of tumor angiogenesis and metastasis (12-14). The antiproliferative properties of anandamide were also demonstrated in vivo, where it induced inhibition of the activity of the K-ras oncogene product, p21ras, thereby leading to the reduction of tumor growth (15).

Moreover, a correlation between anandamide and the progression of hepatic diseases was suggested by the observation that high plasma levels of anandamide were found in patients with severe hepatitis or advanced cirrhosis and massive hepatocellular damage (16).

In the last few years, we have investigated the apoptotic action of a number of drugs in different hepatoma cell lines (17-20). The present study was focused on the effects exerted by anandamide on several human hepatic cell lines (Chang liver, HepG2, HuH-6, SK-Hep1). We observed a different susceptibility of these cells to the drug, since anandamide induced only a modest effect in all hepatoma cell lines tested but was very effective in non-tumor Chang liver cells, where it triggered cell death by stimulating either the extrinsic or intrinsic pathway of apoptosis. The effect was mediated by endogenous ceramide and involved oxidative stress and activation of JNK/AP-1 pathway. 


\section{Materials and methods}

Chemicals and reagents. All compounds were purchased from Sigma (St. Louis, MO) except for z-VAD-fmk (benzyloxy carbonyl-Val-Ala-Asp-fluoromethylketone), which was supplied by Promega (Italy). Stock solutions of anandamide were dissolved in ethanol and diluted in culture medium. Control cultures were incubated in the presence of vehicle alone.

Monoclonal antibodies for c-Jun (H-79), Jun-B (C-11), c-Fos (D-1), Fra-1 (N-17), Bax (B-9), Bim (FL-198), Bid (C-20), FasL (Q-20), JNK1 (F-3) and phosho-JNK (G-7) were purchased from Santa Cruz Biotechnology (Santa Cruz, CA, USA). Antibodies against phospho-c-Jun (Ser-63), phosphoMKK3/MKK6 (Ser189/207), phospho-SEK1/MKK4 (Ser257/ Thr261), p38 MAPK , phospho-p38 MAPK (Thr180/Tyr182), caspase-3, and caspase 8 (1C12) were obtained from Cell Signaling Technology (Beverly, MA). Anti-caspase-6 antibody was purchased from Sigma.

Cell cultures. Human hepatic Chang liver cells and hepatoma HepG2, HuH-6 and SK-Hep1 cells were cultured in RPMI1640 medium supplemented with $10 \%$ heat-inactivated fetal calf serum (FCS), $1 \%$ sodium pyruvate and 1\% L-glutamine and maintained at $37^{\circ} \mathrm{C}$ with $5 \% \mathrm{CO}_{2}$ in a humid environment.

For the experiments, cells were seeded on 96-well plates or 6-well plates at $60-70 \%$ confluence. Twenty-four hours after seeding, cells were kept in serum-free medium for $6 \mathrm{~h}$ before the addition of anandamide.

Cell viability assay. The effect of anandamide on cell viability was determined by 3-[4,5-dimethylthiazolyl-2] 2,5-diphenyltetrazolium bromide (MTT) assay. After incubation with the compounds, MTT reagent was added to the cultures and the assay was carried out as previously reported (18). Values reported in figures are expressed as percentage of the viability of control cells. The absorbance at $570 \mathrm{~nm}$ (test wavelength) and $630 \mathrm{~nm}$ (reference wavelength) was measured using an ELISA microplate reader.

Hoechst staining. Cells seeded in 96-well plates were washed in PBS and stained for $10 \mathrm{~min}$ at room temperature in PBS containing $40 \%$ paraformaldehyde and $10 \mu \mathrm{g} / \mathrm{ml}$ Hoechst 33258. Morphological evaluations of nuclear condensation and fragmentation were performed immediately after staining by means of fluorescent microscope.

Quantification of apoptosis by flow cytometry. After treatment with the compounds, cells were harvested by trypsinization and resuspendend in a hypotonic solution containing $50 \mu \mathrm{g} / \mathrm{ml}$ propidium iodide, $0.1 \%$ sodium citrate, $0.01 \%$ Nonidet P-40 and $10 \mu \mathrm{g} / \mathrm{ml}$ RNase A and incubated overnight at $4^{\circ} \mathrm{C}$. Cell cycle phase distribution was evaluated by an Epics XL flow cytometer (Beckman Coulter) using Expo32 software. The percentage of cells in the subdiploid region was considered as an index of apoptosis.

Measurement of $\Delta \psi_{m}$. Mitochondrial transmembrane potential $\left(\Delta \psi_{\mathrm{m}}\right)$ dissipation was measured by using 3,3-dihexyloxacarbocyanine $\left(\mathrm{DiOC}_{6}\right)$. Chang liver cells were harvested by trypsinization, treated with $40 \mathrm{nM} \mathrm{DiOC}_{6}$ for $20 \mathrm{~min}$ and analysed by flow cytometry. The percentage of cells showing a lower fluorescence, reflecting loss of $\Delta \psi_{\mathrm{m}}$, was determined by comparison with untreated controls.

Western blot analysis. After treatment, cells were washed in PBS and incubated in ice-cold lysis buffer containing protease inhibitor cocktail for $20 \mathrm{~min}$, as previously reported (17). Then, cells were sonicated three times for $10 \mathrm{sec}$ and the protein content evaluated using the Lowry method. Equal amounts of protein samples $(60 \mu \mathrm{g} / \mathrm{lane})$ were subjected to SDSpolyacrylamide gel electrophoresis and then transferred to a nitrocellulose membrane for detection with specific antibodies. Bands were quantified by densitometric analysis. The correct protein loading was verified by means of both red Ponceau staining and immunoblotting for actin.

Electrophoretic mobility shift assay (EMSA). EMSA was performed using Gel Shift Assay System (Promega, Italy). For this study, double-stranded oligonucleotide containing the AP1 binding site (5'-TCG ACA TCT CAA TTA GTC AGC AAG-3') was labelled to 5'-end using T4 polynucleotide kinase in the presence of $\left[\gamma-{ }^{32} \mathrm{P}\right]-\mathrm{ATP}$. Equal amounts of nuclear extracts (10 $\mu \mathrm{g}$ of proteins), prepared according to Schreiber et al (21) as described by Rabinovich (22), were incubated in the presence of $3 \mu \mathrm{g}$ of poly (dI-dC) in EMSA buffer for $10 \mathrm{~min}$ at $4^{\circ} \mathrm{C}$. Then, the labelled oligonucleotide was added $\left(2 \times 10^{5}\right.$ c.p.m. $)$ and the reaction mixture was incubated for $20 \mathrm{~min}$ at $25^{\circ} \mathrm{C}$. Complexes were resolved on $4 \%$ native polyacrylamide gel in $1 \mathrm{X}$ TBE at $100 \mathrm{~V}$ for $1 \mathrm{~h}$. Band shift mobility was detected by autoradiography of dried gels using Kodak film with an intensifying screen for approximately $16 \mathrm{~h}$ at $-80^{\circ} \mathrm{C}$.

The specificity of the binding was examined by competition assays incubating the extracts for 10 min with a 100-fold excess of either specific or non-specific unlabeled oligonucleotides before the addition of ${ }^{32} \mathrm{P}$-labeled probe.

Supershift assay. Nuclear extracts were incubated with $2 \mu \mathrm{g}$ of specific antibodies against c-Jun, Jun-B, c-Fos, and Fra1 in the presence of the radiolabelled $\mathrm{AP}-1$ probe at $25^{\circ} \mathrm{C}$ for $45 \mathrm{~min}$. The individual samples were then resolved by electrophoresis on $4 \%$ native polyacrylamide gel and detected as described above (17).

\section{Results}

Apoptotic effects of anandamide in different hepatic cell lines. We first evaluated the cell viability by means of MTT assay either in Chang liver cells, an immortalised non-tumor cell line, or in three different lines of hepatoma cells (HepG2, HuH-6 and SK-Hep1).

As shown in Fig. 1A, anandamide induced a clear decrease in the viability of Chang liver cells. The effect, which was dose-dependent, was observed at a range of 2.5-15 $\mu \mathrm{M}$. At $24 \mathrm{~h}$ of treatment, the number of viable cells decreased to $28 \%$ with $10 \mu \mathrm{M}$ anandamide and $15 \%$ with $15 \mu \mathrm{M}$. In contrast, all of the hepatoma cells exhibited only a little susceptibility to the drug. In fact, with $15 \mu \mathrm{M}$ anandamide, the number of viable HuH-6 or SK-Hep1 cells did not drop below 55\% and 
A

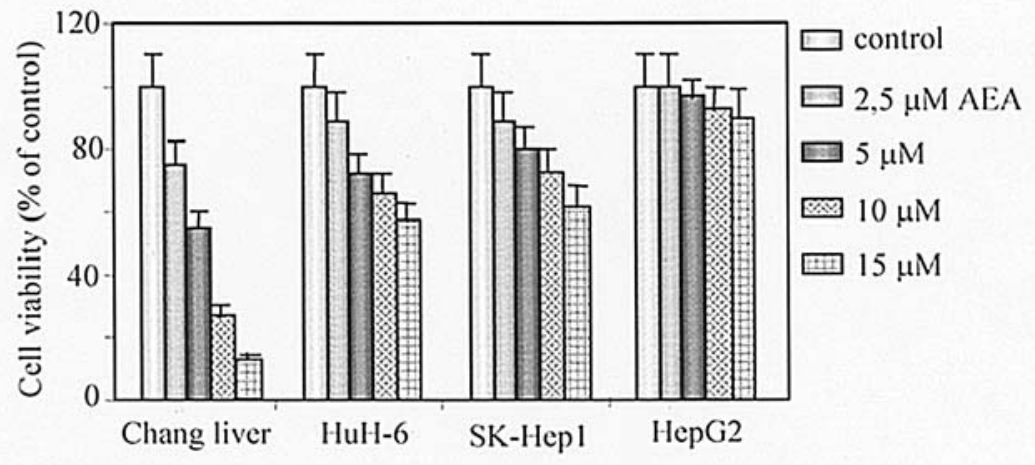

B

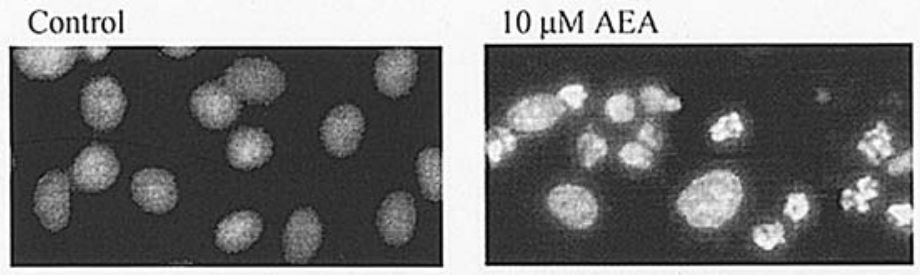

C
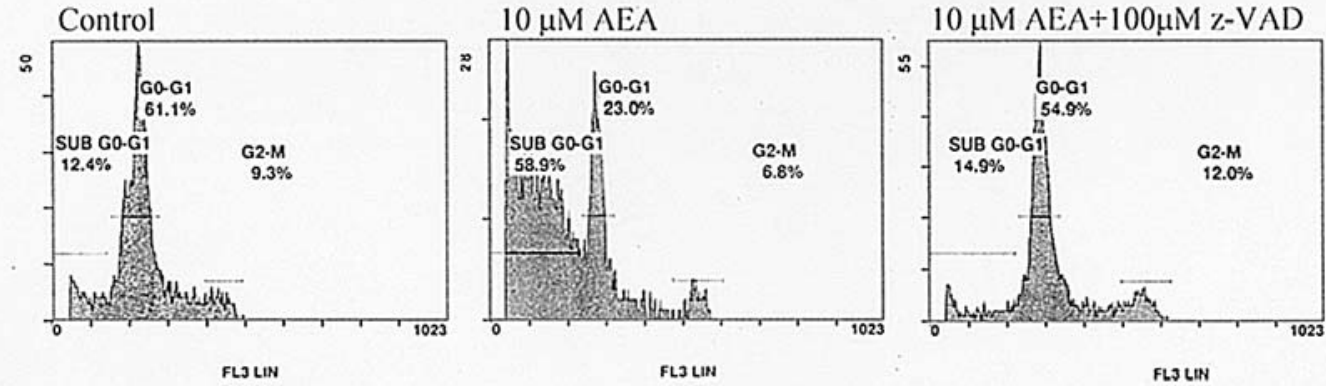

Figure 1. Apoptotic effects induced by anandamide in different hepatic cell lines. (A) Cells were treated with vehicle (control) or with the indicated concentrations of anandamide (AEA). Cell viability was estimated at $24 \mathrm{~h}$ of treatment by MTT assay, as reported in Materials and methods. The results are indicated as the percentage of viable cells with respect to untreated controls. Data represent the average \pm SD of six independent experiments performed in triplicate. (B) Morphological analysis of Chang liver cells treated with $10 \mu \mathrm{M}$ anandamide for $24 \mathrm{~h}$. Fluorescence microscopy after Hoechst 33258 nuclear staining was employed to detect typical chromatin changes. A representative experiment (of four) is shown. (C) Flow cytometric analysis of cell cycle distribution of Chang liver cells after incubation with $10 \mu \mathrm{M}$ anandamide for $24 \mathrm{~h}$ without or with $100 \mu \mathrm{M} \mathrm{z}$-VAD-fmk. Cells were stained with propidium iodide as described in Materials and methods. The percentage of cells in different phases of the cycle was calculated using Expo32 software. The results of a representative experiment (of four) are shown.

HepG2 cells appeared almost insensitive to treatment, showing a decrease in cell viability of only $10 \%$.

Then, we assessed whether the cytotoxicity induced by anandamide was associated with the induction of apoptosis. Morphological evaluation of Chang liver cells using Hoechst 33258 staining and fluorescent microscopy revealed a marked increase in the number of cells with nuclear condensation and fragmentation after $24 \mathrm{~h}$ of treatment with $10 \mu \mathrm{M}$ anandamide (Fig. 1B). These results were confirmed by flow cytometric analysis after staining the cells with propidium iodide. The intensity of apoptotic effect was indicated by the percentage of cells with subdiploid DNA confined to the subG0/G1 phase of the cell cycle. Fig. 1C shows that this was approximately $60 \%$ in Chang liver cells after $24 \mathrm{~h}$ of treatment with $10 \mu \mathrm{M}$ anandamide. The addition of $100 \mu \mathrm{M} \mathrm{z}$-VAD, a general caspase inhibitor, counteracted anandamide's effect on DNA fragmentation, suggesting that caspases are involved in the death program induced by the drug in these non-tumor cells.

Cytometric analysis confirmed that anandamide induced only a modest effect in hepatoma cells. In fact, under the same experimental conditions, the percentage of cells confined to the subG0/G1 phase was only $25 \%$ in HuH-6 and SK-Hep1 cells while, in HepG2 cells, it was similar to that observed in untreated controls (not shown).

Cholesterol-dependent cytotoxic action of anandamide in Chang liver cells. It is well known that anandamide interacts with its targets mainly through CB1, CB2 and VR1 receptors. Recently, another mechanism used by the drug has been reported which involves cholesterol-rich membrane microdomains known as lipid rafts. In order to ascertain whether the apoptotic effect induced by anandamide was mediated by 


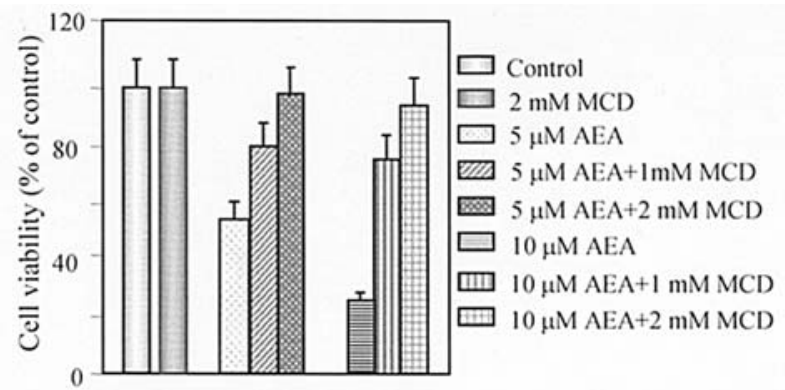

Figure 2. The influence of the membrane cholesterol depletor, methyl- $\beta$ cyclodextrin, on the anandamide effect in Chang liver cells. Cells were pretreated for $1 \mathrm{~h}$ with the indicated concentrations of methyl- $\beta$-cyclodextrin (MCD). Then, 5 or $10 \mu \mathrm{M}$ anandamide (AEA) was added and the incubation was protracted for $24 \mathrm{~h}$. Cell viability was estimated by MTT assay, as reported in Materials and methods and the results expressed as in Figure 1.

such lipid domains in Chang liver cells, we employed methylß-cyclodextrin (MCD), a specific depletor of membrane cholesterol which disrupts the integrity of lipid rafts (6). The experiment reported in Fig. 2 confirmed that pre-treatment with increasing concentrations of MCD reduced the effects induced by anandamide on Chang liver cell viability so that the addition of $2 \mathrm{mM}$ MCD almost completely prevented the effect of the drug.

Involvement of ceramide and oxidative stress in anandamideinduced apoptosis. It has been reported that anandamide, through interaction with its receptors, can induce hydrolysis of sphingomyelin with the production of ceramide, an effective activator of the death program (23-24). To verify whether ceramide plays a role in the apoptotic mechanism induced by anandamide in Chang liver cells, we treated the cells with desipramine, which is a powerful inhibitor of sphingomyelinase (25). As shown in Fig. 3A, the addition of $10 \mu \mathrm{M}$ desipramine almost completely counteracted the effect induced by $5 \mu \mathrm{M}$ anandamide, and markedly reduced that observed with $10 \mu \mathrm{M}$. In addition, treatment of Chang liver cells with melittin, a non-specific activator of sphingomyelinase (26), induced an apoptotic effect like that observed in cells treated with anandamide. The effect was dosedependent so that cell viability was reduced by approximately $65 \%$ after $24 \mathrm{~h}$ of treatment with melittin at a concentration of $500 \mathrm{ng} / \mathrm{ml}$ (Fig. 3B). These results strongly suggested that ceramide can be a mediator in anandamide-induced apoptosis. The hypothesis was confirmed by experiments performed in the presence of $\mathrm{C} 2$-ceramide, a cell-permeable ceramide analogue. Fig. 3C shows that C2-ceramide dose-dependently decreased Chang liver cell viability which reached $28 \%$ of the control value at a dose of $50 \mu \mathrm{M}$ while, in HepG2 cells, C2-ceramide was much less effective.

Since ceramide production is often accompanied by oxidative stress, we wanted to ascertain whether $\mathrm{N}$-acetyl cysteine (NAC), a thiol reducing agent that raises the intracellular GSH pool and prevents the action of ROS, was capable of counteracting anandamide's effect. Pre-treatment of Chang liver cells for $1 \mathrm{~h}$ with NAC dose-dependently prevented the cells from the cytotoxic effect of the drug. As shown in Fig. 3D, the addition of $10 \mathrm{mM}$ NAC suppressed the effect induced by $10 \mu \mathrm{M}$ anandamide for $24 \mathrm{~h}$.

Effect of anandamide on the activation of p38/JNK pathway and AP-1 DNA-binding activity. Previous studies have shown that oxidative stress often causes the activation of $\mathrm{p} 38 / \mathrm{JNK}$ pathway (27). We investigated the possible involvement of
A

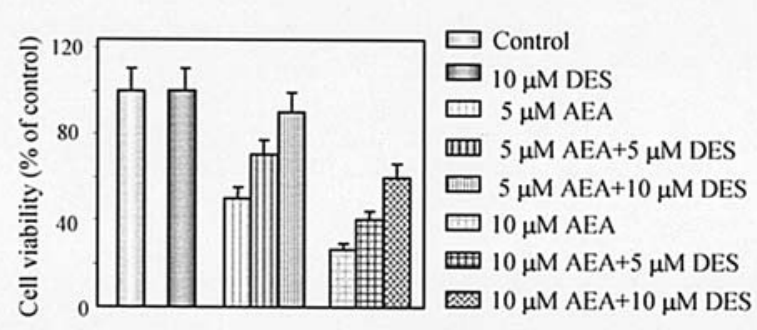

C

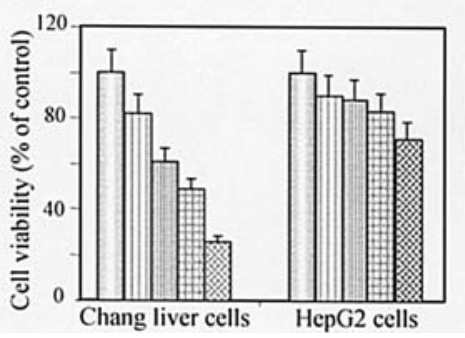

B

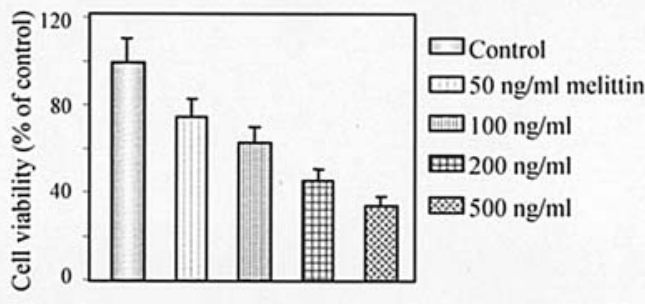

D

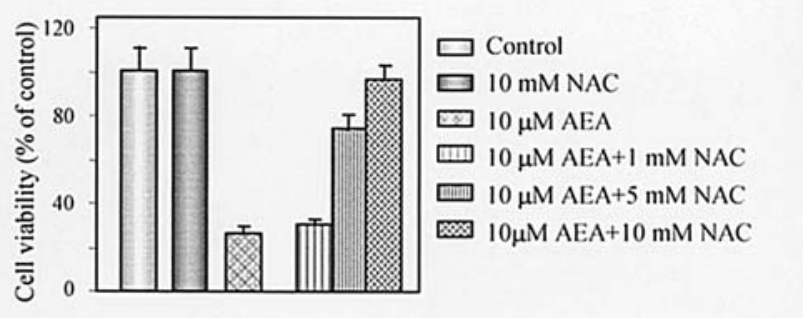

Figure 3. The involvement of ceramide and oxidative stress in anandamide-induced apoptosis in Chang liver cells. Chang liver cells were treated for $24 \mathrm{~h}$ with 5 or $10 \mu \mathrm{M}$ anandamide (AEA) and without or with the indicated doses of the sphingomyelinase inhibitor, desipramine (DES) (A), with the sphingomyelinase activator melittin (B), with exogenous C2-ceramide (C), or pre-treated for 30 min with the indicated concentrations of the antioxidant N-acetyl-cysteine (NAC), followed by incubation for $24 \mathrm{~h}$ with $10 \mu \mathrm{M}$ anandamide (D). Cell viability was estimated by MTT assay, as reported in Materials and methods. The results are indicated as the percentage of viable cells with respect to untreated controls. Data represent the average \pm SD of five independent experiments performed in triplicate. 

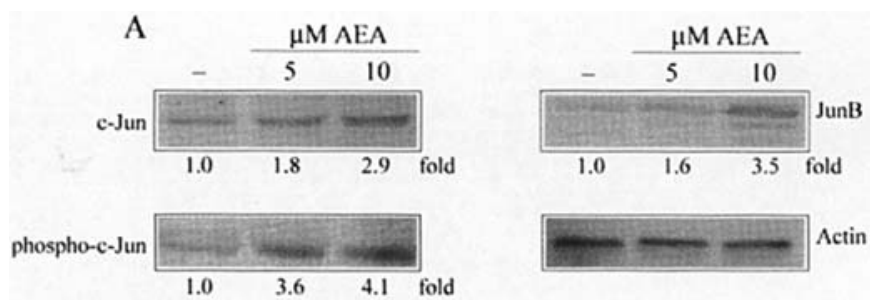

B
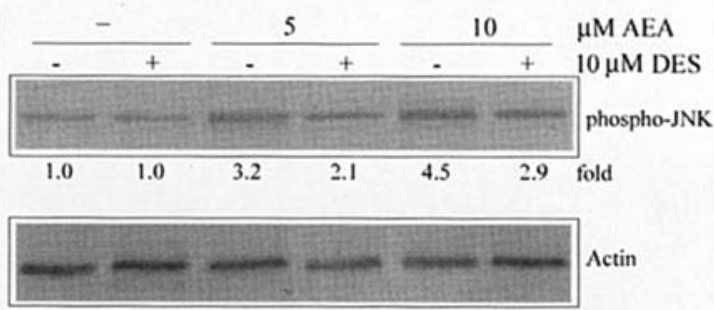

C
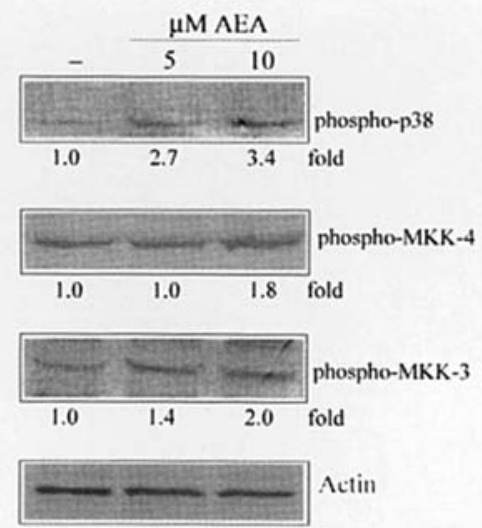

Figure 4. The effects of anandamide on the levels of various factors related to c-Jun/JNK pathway. After treatment for $24 \mathrm{~h}$ with the indicated doses of anandamide (AEA), Chang liver cells were lysed and analysed by Western blotting for the expression levels of c-Jun, phospho-c-Jun, and Jun B (A); phospho-JNK (B); phospho-p38, phospho-MKK-4, and phospho-MKK-3 (C). The effect induced by $10 \mu \mathrm{M}$ desipramine (DES) on the level of phospho-JNK was also analysed in the experiment of panel B. For each experiment, an actin blot is included to show equal protein loading for all the samples. Bands were quantified by densitometric analysis using SMX Image software. The results are representative of four independent experiments.

this pathway in apoptosis induced by anandamide in Chang liver cells. Fig. 4A shows that treatment with $10 \mu \mathrm{M}$ anandamide increased the level of both c-Jun and its phosphorylated form by approximately 2.9- and 4.1-fold over the control value, respectively, after $24 \mathrm{~h}$ of treatment. Moreover, the level of Jun-B, another factor of the c-Jun family, also increased by 3.5-fold after treatment.

The members of the c-Jun family are phosphorylated by different MAP kinases, such as c-Jun N-terminal kinase (JNK) and p38/MAPK. As shown in Fig. 4B, $10 \mu \mathrm{M}$ anandamide induced a 4.5 -fold increase in the phosphorylated form of JNK, observed by using a phospho-specific SAPK/JNK (Thr183/Tyr185) antibody. In contrast, the level of total JNK protein was not changed by anandamide exposure (not shown). To demonstrate the direct correlation between the increase in intracellular ceramide and the activation of JNK pathway, we analysed the effect of desipramine on the levels of phos-

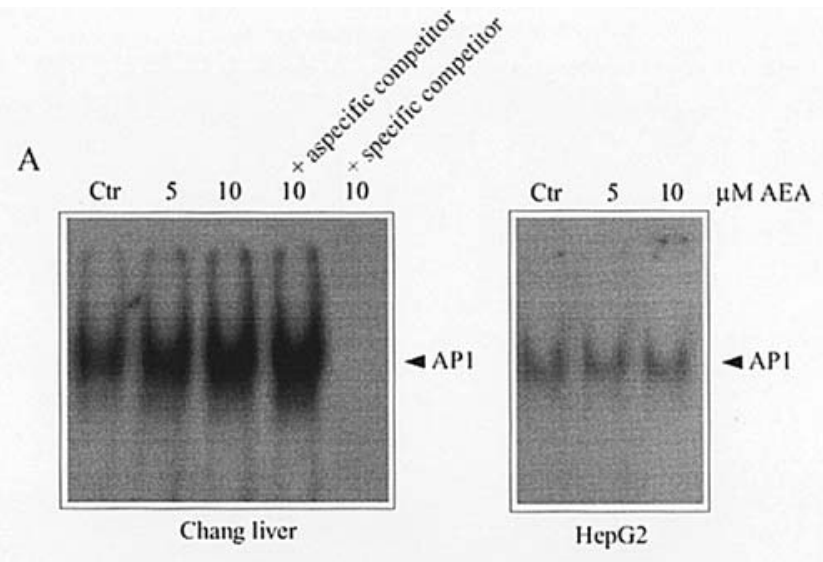

B

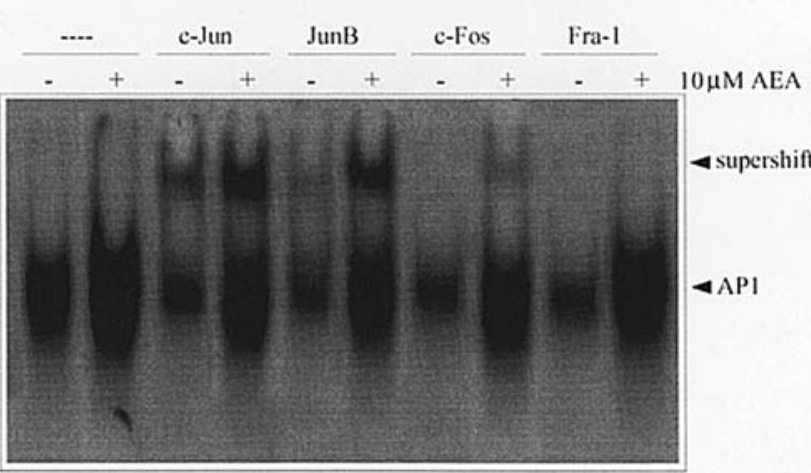

Figure 5. The effects of anandamide on AP-1 DNA-binding activity (A) and composition (B). Chang liver and HepG2 cells were cultured for $24 \mathrm{~h}$ without or with 5 or $10 \mu \mathrm{M}$ anandamide (AEA). (A) Nuclear extracts, prepared as reported in Materials and methods, were subjected to EMSA after incubation with ${ }^{32} \mathrm{P}$-labelled AP-1 probe. For competitive experiments, nuclear extracts were incubated with 100-fold excess of specific or aspecific cold oligonucleotide competitors as indicated. (B) Nuclear extracts, prepared from Chang liver cells, were submitted to supershift analysis of AP-1 complex. Antibodies ( $2 \mu \mathrm{g}$ ) against c-Jun, Jun B, c-Fos or Fra-1 were added to the extracts in the presence of ${ }^{32} \mathrm{P}$-labelled probe, as reported in Materials and methods. Complexes were resolved by electrophoresis and detected by autoradiography of dried gels. The results were representative of three independent experiments.

phorylated forms of JNK and c-Jun. As shown in Fig. 4B, the addition of $10 \mu \mathrm{M}$ desipramine clearly reduced the effect of anandamide on phospho-JNK. Similar results were observed with the phospho-c-Jun level (not shown).

In parallel experiments, we examined p38/MAPK activity by using an antibody recognizing the (Thr180/Tyr182)phosphorylated/activated form of the enzyme. The results reported in Fig. 4C indicate that the phospho-p38 level was increased after treatment with anandamide (3.4-fold with $10 \mu \mathrm{M})$. Moreover, in anandamide-treated cells, we observed a dose-dependent increase in the level of MKK-4 (also termed SEK-1 or JNKK) and MKK-3, which are the kinases upstream in JNK and p38 cascade, respectively (Fig. 4C).

Because phospho-c-Jun was the main component of transcription factor AP-1, we performed EMSA experiments in order to verify eventual changes in AP-1 DNA-binding activity in anandamide-treated Chang liver cells. Fig. 5A shows that treatment with anandamide induced a dosedependent increase in AP-1 DNA-binding activity. Also in 

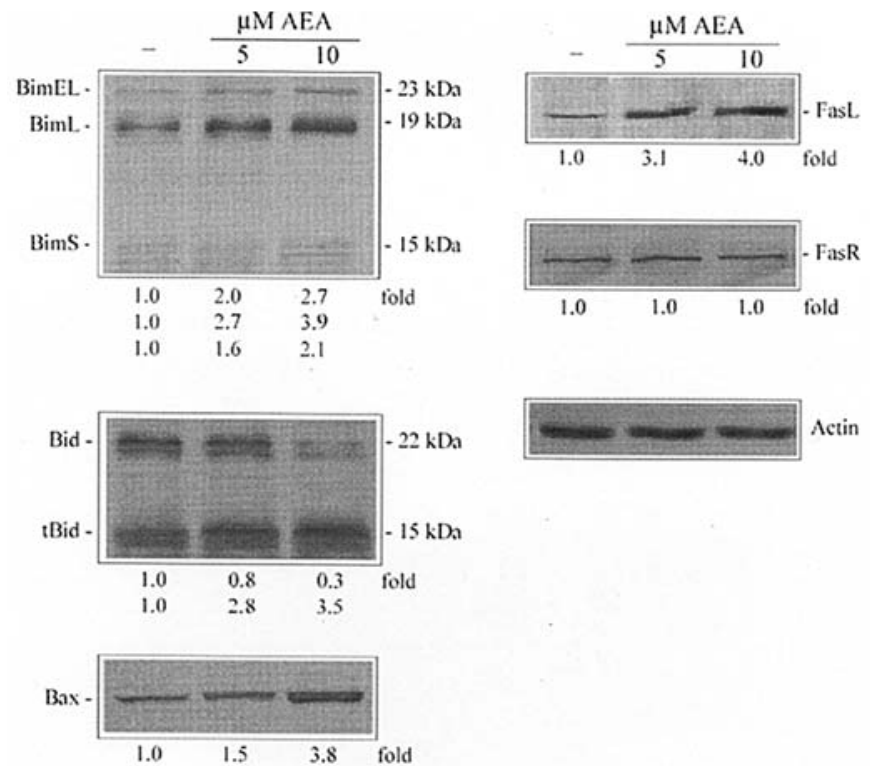

Figure 6. The effects of anandamide on the levels of some apoptotic factors. After treatment for $24 \mathrm{~h}$ with 5 or $10 \mu \mathrm{M}$ anandamide (AEA) Chang liver cells were lysed and analysed by Western blotting for the expression level of the indicated proteins, as reported in Materials and methods. For each experiment, an actin blot is included to show equal protein loading for all samples. Bands were quantified by densitometric analysis using SMX Image software. The results are representative of four independent experiments.

this case, the addition of desipramine caused a marked reduction of anandamide's effect on AP1 activity (not shown). AP-1 binding specificity was demonstrated by competition experiments in the presence of a 100-fold excess of specific or aspecific cold oligonucleotides. In contrast, in anandamidetreated HepG2 cells, it was not possible to observe any variation in AP-1 DNA-binding activity.

Furthermore, we investigated the composition of the AP1 complex by means of supershift analysis using antibodies against different Fos and Jun family members (c-Jun, JunB, c-Fos and Fra-1).

The results reported in Fig. 5B indicated that, under our experimental conditions, c-Jun and Jun-B were the main components of the AP-1 complex while Fos represented a minor component. Finally, Fig. 5B suggested that Fra1 was absent in the AP-1 complex, since the antibody against this factor did not modify the electrophoretic mobility of AP-1.

Effect of anandamide on Bcl-2 family proteins and members of the Fas pathway. It is well known that Bcl-2 family members play an important role in the apoptotic mechanism (28). In Chang liver cells treated with $10 \mu \mathrm{M}$ anandamide, Western blot analysis showed only a modest decrease in the levels of Bcl-2 and Bcl-XL, which are two anti-apoptotic factors of the family (not shown). Interestingly, we observed a clear increase in the levels of Bim, Bid and Bax, three pro-apoptotic factors of the Bcl-2 family.

Bim is a factor of the BH3-only subfamily, which is present in cells in three different isoforms (BimEL, BimL and BimS). Anandamide induced an increase in the level of the three isoforms, particularly in that of BimL (3.9-fold respect to the control) (Fig. 6). Moreover, treatment with the drug caused a dose-dependent decrease in the level of native
Bid together with the appearance of a band of $15 \mathrm{kDa}$, corresponding to the truncated and active form of the protein (Fig. 6). Also, a clear increase in the level of Bax was observed in treated cells.

Since Fas pathway can be triggered by transcriptional activity of AP-1, we analysed the level of both Fas receptor and Fas ligand (FasL). The expression of Fas receptor was not modified by anandamide treatment, while the drug clearly increased the FasL level, which reached a 4-fold value over the control in the presence of $10 \mu \mathrm{M}$ anandamide (Fig. 6).

Involvement of mitochondria and caspase activities in anandamide-induced apoptosis. The evaluation of mitochondrial transmembrane potential $\left(\Delta \psi_{\mathrm{m}}\right)$ using $\mathrm{DiOC}_{6}$, a fluorescent voltage-dependent dye, showed that treatment with $10 \mu \mathrm{M}$ anandamide for $24 \mathrm{~h}$ induced the dissipation of $\Delta \psi_{\mathrm{m}}$ with the increase in percentage of depolarised cells. The addition of $100 \mu \mathrm{M} \mathrm{z}$-VAD partially counteracted ( 50\%) the loss in mitochondrial transmembrane potential induced by the drug (Fig. 7A).

In order to ascertain the involvement of caspase activity in anandamide-induced apoptosis, we analysed the level of caspase- 8 , an upstream protease, and that of caspase- 3 and -6 , two proteases of the execution phase of apoptosis, using Western blotting. The results reported in Fig. 7B indicate that treatment for $24 \mathrm{~h}$ with 5 or $10 \mu \mathrm{M}$ anandamide induced a marked activation of caspase- 8 , as demonstrated by the decrease in intensity of the $57-\mathrm{kDa}$ band, corresponding to procaspase-8, together with the appearance of the $43-\mathrm{kDa}$ band which is recognised as the active form. Fig. 7B also shows the activation of caspase- 3 , as indicated by the decrease of the proenzyme (band at $32 \mathrm{kDa}$ ) and the concomitant increase in the level of the active form of $17 \mathrm{kDa}$. Finally, anandamide also induced a clear decrease in the level of procaspase-6 (Fig. 7B). However, in this case, the degraded form was not observed since it is not recognised by the antibody used in the experiment.

\section{Discussion}

In the last few years, many investigations have focused on the effects exerted by endogenous cannabinoids. These factors have been recently found to suppress cell proliferation or induce apoptosis in many in vivo and in vitro systems (12).

In the present study, we investigated the effect of anandamide in human Chang liver cells, a model of normal hepatocytes, and in three different lines of hepatoma cells. We demonstrated by both MTT assay and cytofluorimetric analysis that anandamide efficiently reduced the viability of Chang liver cells in a dose-dependent manner but was much less effective in hepatoma cells. Anandamide-treated Chang liver cells show typical morphological signs of apoptosis, such as chromatin condensation and fragmentation, as demonstrated by Hoechst staining. Moreover, the caspase inhibitor, z-VAD, completely prevented Chang liver cells from anandamideinduced apoptosis, indicating that caspase activities are involved in cell death.

It is well known that, in many cells, the effects of anandamide, independently from the presence of specific receptors, are mediated by cholesterol rich membrane microdomains, 

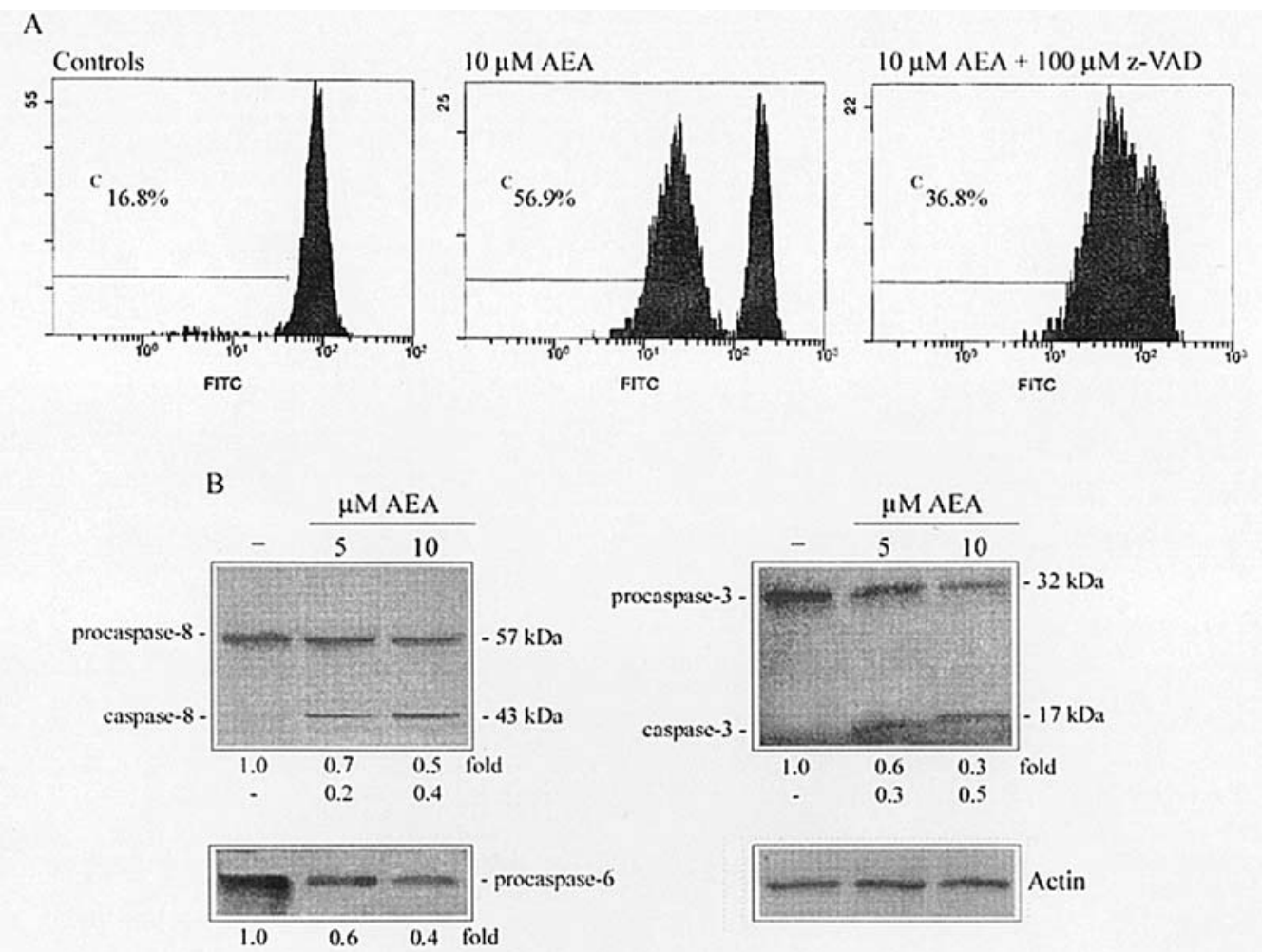

Figure 7. The involvement of mitochondria and caspase activity in anandamide-induced apoptosis. (A) Determination of dissipation of mitochondrial transmembrane potential $\left(\Delta \psi_{\mathrm{m}}\right)$ in Chang liver cells treated for $24 \mathrm{~h}$ with $10 \mu \mathrm{M}$ anandamide (AEA) without or with $100 \mu \mathrm{M} \mathrm{z}-\mathrm{VAD}$-fmk. $\Delta \psi_{\mathrm{m}}$ was measured by flow cytometry after staining with the lipophilic dye, $\mathrm{DiOC}_{6}$, as reported in Materials and methods. Data are representative of three separate experiments with similar results. (B) Activation of caspase activity in anandamide-treated Chang liver cells. Lysates were prepared by cells treated for $24 \mathrm{~h}$ with 5 or $10 \mu \mathrm{M}$ anandamide and analyzed by Western blotting as reported in Materials and methods. For each experiment, an actin blot is included to show equal protein loading for all samples. Bands were quantified by densitometric analysis using SMX Image software. The results are representative of four independent experiments.

known as lipid rafts. Since the addition of the cholesterol depletor, methyl-ß-dextrin, completely counteracted anandamide-induced apoptosis in Chang liver cells, we postulate that anandamide mainly acts through lipid rafts in these cells. Results reported in this paper demonstrate that, in Chang liver cells, treatment with melittin, a sphingomyelinase activator, mimicked the effect induced by anandamide while the addition of the sphingomyelinase inhibitor, desipramine, markedly counteracted the effect of the drug. These data strongly suggest that ceramide is involved in anandamide-induced apoptosis. In accordance with this hypothesis, our data indicate that $\mathrm{C} 2$ ceramide, a cell-permeable ceramide analogue, provoked a remarkable reduction in Chang liver cell viability at a range of $5-50 \mu \mathrm{M}$.

Our paper provides evidence that anandamide induced apoptosis in Chang liver cells by means of a mechanism which is mediated by JNK/p38 activity and the transcription factor, AP-1. Treatment with the drug did not modify the basal level of JNK proteins, while it increased the level of their phosphorylated forms as well as the level of phospho-MKK-4 and MKK-3, the kinases upstream to JNK and p38 respectively. In addition, since the sphingomyelinase inhibitor, desipramine, prevented the phosphorylation/activation of JNK, we think that ceramide, which was produced under anandamide stimulation, could be responsible for the induction of JNK/p38 pathway. Ceramide could induce JNK/p38 pathway either through direct activation of the upstream kinase of JNK cascade MEKK-1, as reported by Huwiler et al (29) in glomerular endothelial cells, or through the generation of oxidative stress, which is the main activator of JNK. The observation that the addition of NAC, the most active antioxidant agent, completely prevented anandamide-induced cell death in Chang liver cells, seems to indicate a possible role of oxidative stress in the apoptotic pathway induced by the drug. However, our data did not clearly indicate the direct targets of ceramide action in Chang liver cells.

Another interesting event is the marked increase in the level of phospho-c-Jun, which was observed in Chang liver cells treated with anandamide. This event, which was obviously a closed consequence of JNK activation, contributed to stabilising AP-1 and increasing its DNA-binding activity in treated Chang liver cells. The observation that desipramine also inhibited AP-1 DNA-binding activity is evidence that AP-1 was activated by ceramide. Therefore, ceramide, JNK and AP-1 seem to relate to each other in order to mediate apoptosis induced by anandamide.

AP-1 is a transcriptional factor which plays an important role in determining survival or cell death (30). Our results suggest that AP-1 stimulated apoptosis in Chang liver cells by inducing the expression of FasL and Bim, two apoptotic factors which are transcriptional targets of AP-1. The marked increase in the level of FasL was evidence that anandamide induced death in Chang liver cells by stimulating the extrinsic pathway of apoptosis. The involvement of FasL resulted in 
the activation of caspase- 8 with degradation of full-length Bid and the production of its active form, tBid. Finally, our results demonstrate that anandamide also induced a marked increase in the level of Bax, although our results did not clarify the cause of this event. However, in accordance with Kashkar (31), it is possible that ceramide can be involved in the mechanism which stimulated the activation of Bax in Chang liver cells. The increased levels of many pro-apoptotic members of the Bcl-2 family (tBid, Bim and Bax) induced by anandamide were most likely responsible for the dissipation of mitochondrial transmembrane potential and activation of executive caspase- 3 and caspase- 6 .

In conclusion, our results indicate that anandamide triggered apoptosis in Chang liver cells by activating the extrinsic pathway of cell death and inducing mitochondrial damage. The mechanism is most likely stimulated by ceramide and mediated by JNK and AP-1. It is interesting to note that anandamide was unable to induce apoptosis in HepG2 cells. Although it is possible that the different effectiveness of anandamide in the two cell lines depends on a lower uptake of the drug in HepG2 cells, we suggest that it could be a consequence of a different role exerted by ceramide, the mediator of anandamide action. In particular, we advance the hypothesis that ceramide mediates an apoptotic pathway in Chang liver cells whereas, in HepG2 cells, it stimulates a survival mechanism in accordance with recent evidence that ceramide is converted in rat hepatocytes in sphingosine-1phosphate, a factor which induces cell survival by stimulating Akt activity (32).

It is well known that liver fibrosis is a common response to chronic liver injury, ultimately leading to cirrhosis and its complications. A key role in the development of liver fibrosis is played by hepatic stellate cells which, in injured liver, are activated as collagen-producing cells. Thus, the current treatment strategy against liver fibrosis includes the induction of apoptosis in these cells. Recently, it has been reported that anandamide is present at higher levels in the plasma of patients with advanced cirrhosis and it is produced by monocytes activated during the inflammatory process (33). Moreover, Siegmud et al (34) have demonstrated that anandamide inhibits proliferation and induces necrosis in primary hepatic stellate cells, thereby probably exerting antifibrogenic action in liver fibrosis. The results of the present study on the ability of anandamide to induce apoptosis in Chang liver cells, a model of normal hepatocytes in rapid proliferation, suggest that, although the drug could play an anti-fibrotic role, it could also counteract the process of liver regeneration.

\section{References}

1. Di Marzo V, Fontana A, Cadas H, Schinelli S, Cimino G, Schwartz JC and Piomelli D: Formation and inactivation of endogenous cannabinoid anandamide in central neurons. Nature 372: 686-691, 1994.

2. Devane WA, Hanus L, Breuer A, Pertwee RG, Stevenson LA, Griffin G, Gibson D, Mandelbaum A, Etinger A and Mechoulam R: Isolation and structure of a brain constituent that binds to the cannabinoid receptor. Science 258: 1946-1949, 1992.

3. Di Marzo V, De Petrocellis L, Sepe N and Buono A: Biosynthesis of anandamide and related acylethanolamides in mouse $\mathrm{J} 774$ macrophages and N18 neuroblastoma cells. Biochem J 316: 977-984, 1996.
4. Liu J, Gao B, Mirshahi F, Sanyal AJ, Khanolkar AD, Makriyannis A and Kunos G: Functional CB1 cannabinoid receptors in human vascular endothelial cells. Biochem J 346: 835-840, 2000.

5. Smart D, Gunthorpe MJ, Jerman JC, Nasir S, Gray J, Muir AI, Chambers JK, Randall AD and Davis JB: The endogenous lipid anandamide is a full agonist at the human vanilloid receptor (hVR1). Br J Pharmacol 129: 227-230, 2000.

6. Sarker KP and Maruyama I: Anandamide induces cell death independently of cannabinoid receptors or vanilloid receptor 1 : possible involvement of lipid rafts. Cell Mol Life Sci 60: 1200-1208, 2003.

7. Walker JM, Huang SM, Strangman NM, Tsou K and SanudoPena MC: Pain modulation by release of the endogenous cannabinoid anandamide. Proc Natl Acad Sci USA 96: 12198-12203, 1999.

8. Wagner JA, Jarai Z, Batkai S and Kunos G: Hemodynamic effects of cannabinoids: coronary and cerebral vasodilation mediated by cannabinoid CB(1) receptors. Eur J Pharmacol 423: 203-210, 2001.

9. Guzman M, Sanchez C and Galve-Roperth I: Cannabinoids and cell fate. Pharmacol Ther 95: 175-184, 2002.

10. Mimeault M, Pommery N, Wattez N, Bailly C and Henichart JP: Anti-proliferative and apoptotic effects of anandamide in human prostatic cancer cell lines: implication of epidermal growth factor receptor down-regulation and ceramide production. Prostate 56: $1-12,2003$.

11. Contassot E, Wilmotte R, Tenan M, Belkouch MC, Schnuriger V, De Tribolet N, Burkhardt K and Dietrich PY: Arachidonylethanolamide induces apoptosis of human glioma cells through vanilloid receptor-1. J Neuropathol Exp Neurol 63: 956-963, 2004.

12. Guzmàn M: Cannabinoids: potential anticancer agents. Nat Rev Cancer 3: 745-755, 2003.

13. De Petrocellis L, Melck D, Palmisano A, Bisogno T, Laezza C, Bifulco $M$ and Di Marzo V: The endogenous cannabinoid anandamide inhibits human breast cancer cell proliferation. Proc Natl Acad Sci USA 95: 8375-8380, 1998.

14. Maccarrone $M$ and Finazzi-Agrò A: The endocannabinoid system, anandamide and the regulation of mammalian cell apoptosis. Cell Death Differ 10: 946-955, 2003.

15. Bifulco M, Laezza C, Portella G, Vitale M, Orlando P, De Petrocellis L and Di Marzo V: Control by the endogenous cannabinoid system of ras oncogene-dependent tumor growth. Faseb J 15: 2745-2747, 2001

16. Fernandez-Rodriguez CM, Romero J, Petros TJ, Bradshaw H, Gasalla JM, Gutierrez ML, Lledo JL, Santander C, Fernandez TP, Tomas E, Cacho G and Walker JM: Circulating endogenous cannabinoid anandamide and portal, systemic and renal hemodynamics in cirrhosis. Liver Int 24: 477-483, 2004.

17. Lauricella M, Emanuele S, D'Anneo A, Calvaruso G, Vassallo B, Carlisi D, Portanova P, Vento R and Tesoriere G: JNK and AP-1 mediate apoptosis induced by bortezomib in HepG2 cells via FasL/caspase-8 and mitochondria-dependent pathways. Apoptosis (In press).

18. Emanuele S, D'Anneo A, Bellavia G, Vassallo B, Lauricella M, De Blasio A, Vento R and Tesoriere G: Sodium butyrate induces apoptosis in human hepatoma cells by a mitochondria/ caspase pathway, associated with degradation of beta-catenin, $\mathrm{pRb}$ and Bcl-XL. Eur J Cancer 40: 1441-1452, 2004.

19. Giuliano M, Bellavia G, Lauricella M, D'Anneo A, Vassallo B, Vento R and Tesoriere G: Staurosporine-induced apoptosis in Chang liver cells is associated with down-regulation of Bcl-2 and Bcl-XL. Int J Mol Med 13: 565-571, 2004.

20. Emanuele S, Calvaruso G, Lauricella M, Bellavia G, D'Anneo A, Vento R and Tesoriere G: Apoptosis induced in hepatoblastoma HepG2 cells by the proteasome inhibitor MG132 is associated with hydrogen peroxide production, expression of Bcl-XS and activation of caspase-3. Int J Oncol 21: 857-865, 2002.

21. Schreiber E, Matthias P, Muller MM and Schaffner W: Rapid detection of octamer binding proteins with 'mini-extracts', prepared from a small number of cells. Nucleic Acids Res 17: 6419-6420, 1989.

22. Rabinovich GA, Alonso CR, Sotomayor CE, Durand S, Bocco JL and Riera CM: Molecular mechanisms implicated in galectin-1induced apoptosis: activation of the AP-1 transcription factor and downregulation of Bcl-2. Cell Death Differ 7: 747-753, 2000.

23. Galve-Roperh I, Sanchez C, Cortes ML, del Pulgar TG, Izquierdo $\mathrm{M}$ and Guzman M: Anti-tumoral action of cannabinoids: involvement of sustained ceramide accumulation and extracellular signal-regulated kinase activation. Nat Med 6: 313-319, 2000. 
24. Guzmàn M, Galve-Ropher I and Sanchez C: Ceramide: a new second messenger of cannabinoid action. Trends Pharmacol Sci 22: 19-22, 2001.

25. Erdreich-Epstein A, Tran LB, Cox OT, Huang EY, Laug WE, Shimada $\mathrm{H}$ and Millard M: Endothelial apoptosis induced by inhibition of integrins alphavbeta3 and alphavbeta5 involves ceramide metabolic pathways. Blood 105: 4353-4361, 2005.

26. Pellkofer R, Marsh D, Hoffmann-Bleihauer P and Sandhoff K: Melittin stimulates incorporation and degradation of sphingomyelin synaptosomal plasma membranes. J Neurochem 38: 1230-1235, 1982.

27. Murakami T, Takagi H, Suzuma K, Suzuma I, Ohashi H, Watanabe D, Ojima T, Suganami E, Kurimoto M, Kaneto $H$, Honda $\mathrm{Y}$ and Yoshimura N: Angiopoietin-1 attenuates $\mathrm{H}_{2} \mathrm{O}_{2-}$ induced SEK1/JNK phosphorylation through the phosphatidylinositol 3-kinase/Akt pathway in vascular endothelial cells. J Biol Chem 280: 31841-31849, 2005.

28. Breckenridge DG and Xue D: Regulation of mitochondrial membrane permeabilization by BCL-2 family proteins and caspases. Curr Opin Cell Biol 16: 647-652, 2004.

29. Huwiler A, Xin C, Brust AK, Briner VA and Pfeilschifter J: Differential binding of ceramide to MEKK1 in glomerular endothelial and mesangial cells. Biochim Biophys Acta 1636: 159-168, 2004.
30. Shaulian E and Karin M: AP-1 as a regulator of cell life and death. Nat Cell Biol 4: 131-136, 2002.

31. Kashkar H, Wiegmann K, Yazdanpanah B, Haubert D and Kronke M: Acid sphingomyelinase is indispensable for UV light-induced Bax conformational change at the mitochondrial membrane. J Biol Chem 280: 20804-20813, 2005.

32. Osawa Y, Uchinami H, Bielawski J, Schwabe RF, Hannun YA and Brenner DA: Roles for C16-ceramide and sphingosine 1phosphate in regulating hepatocyte apoptosis in response to tumor necrosis factor-alpha. J Biol Chem 280: 27879-27887, 2005.

33. Batkai S, Jarai Z, Wagner JA, Goparaju SK, Varga K, Liu J, Wang L, Mirshahi F, Khanolkar AD, Makriyannis A, Urbaschek R, Garcia N Jr, Sanyal AJ and Kunos G: Endocannabinoids acting at vascular CB1 receptors mediate the vasodilated state in advanced liver cirrhosis. Nat Med 7: 827-832, 2001.

34. Siegmund SV, Uchinami H, Osawa Y, Brenner DA and Schwabe RF: Anandamide induces necrosis in primary hepatic stellate cells. Hepatology 41: 1085-1095, 2005. 